\title{
KORELASI IBU HAMIL RESIKO TINGGI DENGAN KESIAPAN PROGRAM PREMARITAL SKRINING DI PUSKESMAS KOTA SEMARANG
}

\section{CORRELATION OF HIGH RISK PREGNANT WOMEN WITH PREPARED PREMARITAL SCREENING PROGRAM AT PUSKESMAS SEMARANG CITY}

\author{
Dewi Puspitaningrum ${ }^{1}$, Nuke Devi Indrawati' ${ }^{2}$, Indri Astuti Purwanti ${ }^{3)}$ \\ 1),2) Dosen Kebidanan FIKKES University Muhammadiyah Semarang \\ 3) Dosen Kesehatan Masyarakat Universitas Muhammadiyah Semarang \\ Email dewipuspita@unimus.ac.id
}

\begin{abstract}
Abstrak
Pengantar: Salah satu indikator kesehatan adalah Angka Kematian Ibu (AKI) di Indonesia, menurut SDKI 2012 mengalami peningkatan AKI menjadi 359 kematian ibu per 100.000 kelahiran hidup namun menurut hasil SUPAS 2015 AKI mengalami penurunan menjadi 305 kematian ibu per 100.000 kelahiran hidup. Angka Kematian Ibu (AKI) di Kota Semarang. Data tahun 2017 masih banyak resiko yang ditimbulkan pada masa kehamilan yang nanti bisa berdampak pada kelanjutan persalinan, nifas dan bayi yang dilahirkan. Program premarital di Puskesmas sudah ada namun AKI masih tinggi, sehingga kajian tentang pelayanan untuk premarital skrining sangat perlu dikaji pengaruh program premarital skrining dengan kejadian hamil resiko tinggi di Puskesmas Kota Semarang

Metodologi penelitian: Penelitian ini dilakukan di Kota Semarang dengan melalui Puskesmas Kota Semarang sebanyak 37. Dan menggunakan metode kuantitatif dan observasi dengan menggunakan korelasi untuk mengetahui pengaruh program premarital skrining dengan kejadian ibu hamil resiko tinggi di Puskesmas Kota Semarang.

Hasil: Bahwa kejadian infertilitas sekunder anak ke-2 $>5$ tahun mempunyai korelasi dengan kesiapan program premarital dengan nilai $p$ value $<0,05$ (korelasi spearmen) yaitu $p$ value $=0,044$.

Kesimpulan: Perlunya upaya promotif dan preventif dalam pemberian layanan kesehatan yang komprehensif dan efektif bagi wanita sebelum menikah, sehingga bisa mencegah kesulitan saat kehamilan, persalinan dan nifas serta membentuk perencanaan keluarga yang sehat.

Kata kunci: Hamil, Resiko Tinggi, Premarital, Skrining
\end{abstract}

Abstract

Introduction: One health indicator is Maternal Mortality Rate (MMR) in Indonesia, according to IDHS 2012 has increased MMR to 359 maternal deaths per 100,000 live births but according to SUPAS 2015 results MMR decreased to 305 maternal deaths per 100,000 live births. Maternal Mortality Rate (MMR) in Semarang City. Data 2017 is still a lot of risks posed during pregnancy which later may have an impact on the continuation of childbirth, childbirth and babies are born. The premarital program in Puskesmas already exists but the MMR is still high, so the review of premarital screening services needs to be studied by the effect of premarital screening program with high risk pregnancy in Puskesmas Kota Semarang

Research Method: This research was conducted in Semarang City through Puskesmas of Semarang City as much as 37. And using quantitative method and observation by using correlation to know the effect of premarital screening program with high risk pregnancy risk in Puskesmas Kota Semarang

Result: That the incidence of secondary infertility of second child $>5$ years has correlation with readiness of premarital program with $p$ value $<0,05$ (spearmen correlation) that is $p$ value $=0,044$.

Conclusion: The need for promotive and preventive efforts in providing comprehensive and effective health services for women before marriage, so as to prevent difficulties during pregnancy, labor and postpartum as well as configurating a healthy family planning.

Keywords: Pregnant, High Risk, Premarital, Screening 


\section{PENDAHULUAN}

Menurut data WHO, sebanyak 99 persen kematian ibu akibat masalah persalinan atau kelahiran terjadi di negaranegara berkembang. Rasio kematian ibu di negara-negara berkembang merupakan yang tertinggi dengan 450 kematian ibu per 100 ribu kelahiran bayi hidup jika dibandingkan dengan rasio kematian ibu di sembilan negara maju dan 51 negara persemakmuran. Kematian selama kehamilan atau dalam periode 42 hari setelah berakhirnya kehamilan, akibat semua sebab yang terkait dengan atau diperberat oleh kehamilan atau penangananya, tetapi bukan disebabkan oleh kecelakaan/cedera. Keberhasilan upaya kesehatan salah satu indikator yang peka dalam menggambarkan kesejahteraan masyarakat suatu negara adalah indikator Angka Kematian Ibu. Menurut data SDKI 2012 yang mengalami peningkatan AKI menjadi 359 kematian ibu per 100.000 kelahiran hidup namun menurut hasil SUPAS 2015 AKI mengalami penurunan menjadi 305 kematian ibu per 100.000 kelahiran hidup.

Selain itu dari data Angka Kematian Ibu (AKI) di Kota Semarang banyak penyebabnya yaitu pre eklamsia, perdarahan dan lain-lain. Dan sebesar 77\% perdarahan di masa nifas, dimana kota Semarang peringkat ke-2 setelah kota Brebes dalam hal AKI (Profil Kesehatan Provinsi Jawa Tengah, 2015). Dalam pelayanan kesehatan yang dekat dengan masyarakat adalah Puskesmas dimana merupakan sarana kesehatan yang melayani layanan primer dalam kesehatan masyarakat dalam upaya preventif dan promotif serta terjangkau bagi semua golongan masyarakat. Dengan melalui Puskesmas dapat memberikan pelayanan yang lengkap dan menjadi upaya preventif AKI. Sehingga masa premarital menjadi penting dalam mempersiapkan baik secara fisik dan mental dalam menjalankan fungsi reproduksinya (Erna,2014).
Dengan kondisi tersebut perlu upaya preventif penurunan AKI salah satunya adalah pemeriksaan premarital skrining. Karena sebagian besar masyarakat umumnya tidak sepenuhnya mengetahui status kesehatannya secara detil, apalagi bagi yang tidak melaksanakan general check up rutin tahunan. Seseorang yang terlihat sehat bisa saja sebenarnya adalah silent carrier/pembawa dari beberapa penyakit infeksi \& hereditas dan saat hamil dapat mempengaruhi janin atau bayi yang dilahirkannya nanti (Kompasiana,2016). Premarital skrining adalah salah satu strategi terpenting untuk mencegah gangguan genetik, dan beberapa masalah medis dan psikososial (Al Sulaiman,2008). Beberapa puskesmas kota semarang sudah ada beberapa pelayanan program premarital. Namun AKI masih tinggi, sehingga kajian tentang pelayanan untuk premarital skrining sangat perlu dikaji korelasi program premarital skrining dengan kejadian hamil resiko tinggi di Puskesmas Kota Semarang.

\section{METODE PENELITIAN}

Metode penelitian yang digunakan pada penelitian ini menggunakan metode kuantitatif dan observasi untuk mengetahui pengaruh premarital skrining dengan kejadian ibu hamil resiko tinggi. Sampel dalam penelitian ini adalah pasien yang melakukan pemeriksaan kehamilan di 37 Puskesmas Kota Semarang, Jawa Tengah, Indonesia selama bulan Februari-April 2018. Data akan diolah dengan menggunakan SPSS versi 17.00. Frekuensi distribusi dengan angka dan porsentase, bivariat dengan korelasi spearmen karena distribusi tidak normal (Sopiyudin,2011)

\section{HASIL DAN PEMBAHASAN}

Hasil penelitian didapatkan pada kejadian ibu hamil resiko tinggi di Puskesmas Kota Semarang Bulan Februari-April 2018 adalah : 
Tabel 1. Distribusi Frekuensi Ibu Hamil Resiko Tinggi Di Puskesmas Sekota Semarang

\begin{tabular}{ll}
\hline \multicolumn{1}{c}{ Variabel } & \\
Ibu Hamil Resti & Jumlah \\
Primimuda $<20$ th & 221 \\
Primitua $>35$ th & 192 \\
Umur $>35^{\text {th }}$ & 346 \\
Infertilitas primer hamil ke-1 $>4$ th & 53 \\
Infertilitas sekunder hamil ke-2 $>5$ th* & 433 \\
Jarak anak $<2$ th & 244 \\
Jumlah anak $\geq 4$ & 134 \\
TB $<145$ cm & 103 \\
LILA $<23.5$ cm & 341 \\
Hb $<11$ gr & 385 \\
Ibu hamil atau sedang menderita resiko & \\
tinggi & \\
Riwayat sedang menderita TBC & 9 \\
Menderita Hipertensi Kronik & 7 \\
Menderita Asma & 5 \\
Menderita jantung & 3 \\
Menderita ginjal & 5 \\
Menderita DM* & 34 \\
Menderita HBSAg $(+)$ & 11 \\
Menderita IMS & 2 \\
Menderita HIV AIDS & 1 \\
\hline
\end{tabular}

Pada hasil tabel 1 menunjukkan bahwa frekuensi hamil resiko tinggi maximum 433, minimum 53 dan rata-rata 245,2. Menunjukkan bahwa yang paling besar adalah ibu hamil resiko tinggi dengan infertilitas sekunder ke- $2>5$ tahun dan paling rendah adalah infertilitas primer. Dan untuk frekuensi riwayat penyakit hamil resiko tinggi maximum 34 , minimum 1 dan rata-rata 8,55 sehingga dapat dilihat bahwa paling besar adalah ibu hamil riwayat penyakit diabetes mellitus, dan paling rendah dengan riwayat penyakit HIV/AIDS.

Bahwa dengan faktor resiko dengan infertilitas sekunder anak ke-2 $>5$ tahun . Infertilitas sekunder terjadi pada wanita yang sudah pernah mempunyai anak, dan ingin mempunyai anak ke-2 jaraknya lama sekali. Sehingga beresiko kaitannya dengan usia ibu yang sudah tidak reproduksi sehat (20-30 tahun), sehingga beresiko nantinya pada kehamilan dan persalinannya seperti mendapatkan anak cacat, persalinan macet dan perdarahan
(Poedji R, 2014). Sehingga kesehatan ibu dan anak sangat bergantung pada kondisi ibu saat sebelum hamil atau sebelum menikah, karena peningkatan status kesehatan seorang wanita sejak sebelum hamil atau sebelum menikah (premarital) sangatlah penting dalam kelangsungan hidup ibu dan anak dengan baik (Erna, 2014).

Pada kejadian ibu hamil resiko dengan riwayat penyakit paling banyak adalah ibu dengan menderita penyakit Diabetes Mellitus (DM). Ibu hamil dengan riwayat penyakit DM merupakan kelainan herediter dengan ciri insufisiensi/ absennya insulin dalam sirkulasi darah, konsentrasi gula darah tinggi dan berkurangnya glikogenesis (Esti,2010). Pencegahan ibu dengan riwayat DM dapat melalui anamnesa riwayat kesehatan dan pemeriksaan gula darah (Hanifa,1999).

Tabel 2 Đistribusi Frekuensi Terbesar Pada Ibu Hamil Resiko Tinggi di Puskesmas Sekota Semarang

\begin{tabular}{ll}
\hline \multicolumn{1}{c}{ Variabel } & Jumlah \\
\hline Infertilitas sekunder hamil ke-2 $>5$ th & 433 \\
Ibu hamil dengan riwayat DM & 34 \\
\hline
\end{tabular}

Tabel 3 Distribusi Frekuensi 37 Puskesmas Di Kota Semarang

\begin{tabular}{|c|c|c|}
\hline Puskesmas & $\begin{array}{l}\text { Infertilitas } \\
\text { sekunder } \\
\text { hamil ke- } \\
2>5 \text { th }\end{array}$ & $\begin{array}{l}\text { Ibu hamil } \\
\text { dengan } \\
\text { riwayat DM }\end{array}$ \\
\hline Puskesmas Poncol & 7 & 0 \\
\hline Puskesmas Miroto & 24 & 0 \\
\hline $\begin{array}{l}\text { Puskesmas } \\
\text { Bandarharjo }\end{array}$ & 35 & 1 \\
\hline Puskesmas Bulu Lor & 19 & 1 \\
\hline $\begin{array}{l}\text { Puskesmas } \\
\text { Halmahera }\end{array}$ & 22 & 0 \\
\hline $\begin{array}{l}\text { Puskesmas } \\
\text { Bugangan }\end{array}$ & 31 & 0 \\
\hline $\begin{array}{l}\text { Puskesmas } \\
\text { Karangdoro }\end{array}$ & 17 & 0 \\
\hline $\begin{array}{l}\text { Puskesmas } \\
\text { Pandanaran }\end{array}$ & 22 & 0 \\
\hline
\end{tabular}




\begin{tabular}{|c|c|c|}
\hline Puskesmas & $\begin{array}{l}\text { Infertilitas } \\
\text { sekunder } \\
\text { hamil ke- } \\
2>5 \text { th }\end{array}$ & $\begin{array}{l}\text { Ibu hamil } \\
\text { dengan } \\
\text { riwayat DM }\end{array}$ \\
\hline $\begin{array}{l}\text { Puskesmas Lamper } \\
\text { Tengah }\end{array}$ & 20 & 0 \\
\hline $\begin{array}{l}\text { Puskesmas } \\
\text { Karangayu }\end{array}$ & 21 & 4 \\
\hline $\begin{array}{l}\text { Puskesmas } \\
\text { Lebdosari }\end{array}$ & 19 & 5 \\
\hline $\begin{array}{l}\text { Puskesmas } \\
\text { Manyaran }\end{array}$ & 23 & 0 \\
\hline $\begin{array}{l}\text { Puskesmas } \\
\text { Krobokan }\end{array}$ & 9 & 4 \\
\hline $\begin{array}{l}\text { Puskesmas } \\
\text { Ngemplak Simongan }\end{array}$ & 8 & 1 \\
\hline $\begin{array}{l}\text { Puskesmas } \\
\text { Gayamsari }\end{array}$ & 35 & 4 \\
\hline $\begin{array}{l}\text { Puskesmas Candi } \\
\text { Lama }\end{array}$ & 8 & 0 \\
\hline Puskesmas Kagok & 4 & 0 \\
\hline $\begin{array}{l}\text { Puskesmas } \\
\text { Pegandan }\end{array}$ & 4 & 0 \\
\hline Puskesmas Genuk & 4 & 0 \\
\hline $\begin{array}{l}\text { Puskesmas } \\
\text { Bangetayu }\end{array}$ & 21 & 0 \\
\hline $\begin{array}{l}\text { Puskesmas Tlogosari } \\
\text { Wetan }\end{array}$ & 0 & 1 \\
\hline $\begin{array}{l}\text { Puskesmas Tlogosari } \\
\text { Kulon }\end{array}$ & 21 & 1 \\
\hline $\begin{array}{l}\text { Puskesmas } \\
\text { Kedungmundu }\end{array}$ & 1 & 0 \\
\hline Puskesmas Rowosari & 2 & 1 \\
\hline Puskesmas Ngesrep & 0 & 3 \\
\hline $\begin{array}{l}\text { Puskesmas } \\
\text { Padangsari }\end{array}$ & 0 & 2 \\
\hline Puskesmas Srondol & 14 & 1 \\
\hline $\begin{array}{l}\text { Puskesmas Pudak } \\
\text { Payung }\end{array}$ & 16 & 0 \\
\hline $\begin{array}{l}\text { Puskesmas Gunung } \\
\text { Pati }\end{array}$ & 0 & 2 \\
\hline Puskesmas Sekaran & 0 & 1 \\
\hline Puskesmas Mijen & 15 & 1 \\
\hline $\begin{array}{l}\text { Puskesmas } \\
\text { Karangmalang }\end{array}$ & 0 & 1 \\
\hline $\begin{array}{l}\text { Puskesmas Tambak } \\
\text { Aji }\end{array}$ & 0 & 0 \\
\hline $\begin{array}{l}\text { Puskesmas } \\
\text { Purwoyoso }\end{array}$ & 11 & 0 \\
\hline Puskesmas Ngaliyan & 0 & 0 \\
\hline $\begin{array}{l}\text { Puskesmas } \\
\text { Mangkang }\end{array}$ & 0 & 0 \\
\hline
\end{tabular}

\begin{tabular}{lcc}
\hline $\begin{array}{l}\text { Puskesmas } \\
\text { Karanganyar }\end{array}$ & 0 & 0 \\
\hline TOTAL & $\mathbf{4 3 3}$ & $\mathbf{3 4}$ \\
\hline
\end{tabular}

Dengan hasil kejadian ibu dengan riwayat infertilitas sekunder hamil ke-2 selama 5 tahun dan ibu hamil dengan riwayat penyakit DM yang paling banyak terjadi beresiko selama 3 bulan pasien yang melakukan pemeriksaan di Puskesmas di Kota Semarang.

Tabel 4 Hasil Uji Normalitas Infertilitas sekunder hamil ke-2 $>5$ tahun dan Ibu Hamil dengan riwayat DM

\begin{tabular}{lccc}
\hline \multicolumn{4}{c}{ Shapiro-Wilk } \\
\hline & Statistic & df & Sig. \\
\hline $\begin{array}{l}\text { Infertilitas } \\
\text { sekunder hamil } \\
\text { ke-2 }>5 \text { th }\end{array}$ & .887 & 37 & .001 \\
\hline $\begin{array}{l}\text { Ibu hamil dengan } \\
\text { riwayat DM }\end{array}$ & .695 & 37 & .000 \\
\hline
\end{tabular}

Tabel 4 menunjukkan uji normalitas bahwa distribusi tiap frekuensi pada ibu dengan infertilitas sekunder hamil ke-2 $>5$ tahun dan ibu hamil dengan riwayat DM didapatkan hasil $p$ value $<0,05$ maka data tersebut berdistribusi tidak normal.

Selain itu dapat dilihat pemeriksaan premarital skrining yang sudah ada di program Puskesmas tersebut adalah sebagai berikut :

Tabel 5 Distribusi Pemeriksaan Premarital Skrining di 37 Puskesmas Kota Semarang

\begin{tabular}{lc}
\hline Pemeriksaan Premarital Skrining & $\mathrm{N}(\%)$ \\
Skrining Komprehensif & $17(45,95)$ \\
Skrining Partial & $20(54,05)$ \\
Total & $\mathbf{3 7 ( 1 0 0 )}$ \\
\hline
\end{tabular}

Pada tabel 5 menunjukkan bahwa 37 puskesmas terdapat 2 jenis skrining premarital yaitu skrining komprehensif sebanyak 17 (45,95\%) dan skrining partial 20 (54,05\%). Pada kategori skrining komprehensif adalah pemeriksaan laboratorium lengkap, fisik dan psikis 
dengan lengkap dibuktikan anamnesa dan hasil pemeriksaan laboratorium yang lengkap serta imunisasi TT calon pengantin, dan skrining partial adalah anamnesa, pemeriksaan PP test,HIV rapid test, Sifilis rapid test dan TT calon pengantin. Pada hasil tersebut bahwa paling banyak diberikan pada premarital skrining adalah skrining partial. Skrining partial mayoritas banyak diberikan pada Puskesmas di Kota Semarang. Menurut Wikipedia skrining komprehensif adalah mengidentifikasi secara lengkap pada individu tanpa tanda atau gejala. Ini dapat termasuk individu dengan gejala simtomatik atau penyakit gejala yang tidak dikenali. Dengan demikian, tes skrining agak tidak biasa karena dilakukan pada orang yang tampaknya dalam keadaan sehat. Dan skrining partial adalah mengidentifikasi sebagian pemeriksaan pada individu dengan gejala simtomatik atau penyakit gejala yang tidak dikenali.

Tabel 6 Hasil Uji Normalitas Premarital Skrining di Puskesmas Kota Semarang

\begin{tabular}{llll}
\hline \multicolumn{4}{c}{ Shapiro-Wilk } \\
\hline & Statistic & df & Sig. \\
\hline Program premarital & .509 & 37 & .000 \\
\hline
\end{tabular}

Hasil uji normalitas pada tabel 6 menunjukkan bahwa karena nilai $p<0,05$ maka premarital skrining tidak berdistribusi normal. Sehingga uji korelasi menggunakan uji korelasi spearmen.

Kemudian diolah dengan korelasi spearmen untuk mengetahui korelasi premarital skrining dengan kejadian ibu hamil resiko tinggi yang paling dominan dengan hasil sebagai berikut:

Tabel 7 Hasil Analisis Bivariat Program Premarital Skrining dengan Kejadian Ibu Hamil Resiko Tinggi

\begin{tabular}{lll}
\hline & $\begin{array}{l}\text { Program } \\
\text { Skrining }\end{array}$ & Premarital \\
\hline $\begin{array}{l}\text { Infertile sekunder hamil } \\
\text { ke- } 2>5 \text { tahun }\end{array}$ & $\mathrm{r}=0,334$ \\
& $p=0.044$ \\
\hline $\begin{array}{l}\text { Ibu hamil dengan } \\
\text { riwayat DM }\end{array}$ & \\
& $p=0,022$ \\
\hline
\end{tabular}

Pada hasil tabel 7 bahwa yang mempunyai nilai $p<0,05$ adalah infertilitas sekunder hamil ke-2 $>5$ tahun dengan $p$ value $=0,044$ yang berhubungan dengan premarital skrining yang ada di Puskesmas Kota Semarang. Sehingga dari hasil tersebut bahwa resiko infertilitas sekunder hamil ke-2 $>5$ tahun bisa terdeteksi melalui premarital skrining, yaitu dengan melalui anamnesa riwayat kesehatan, pola kehidupan sehari-hari dan keluhan-keluhan gangguan kesehatan reproduksi yang sudah di skrining sebelumnya. Dengan kesiapan premarital skrining yang sudah ada sangat bisa membantu skrining awal untuk mengurangi kejadian ibu hamil resiko tinggi dengan riwayat infertilitas sekunder hamil ke-2 $>5$ tahun. Sesuai dengan penelitian lain bahwa premarital skrining adalah salah satu strategi terpenting untuk mencegah gangguan genetik, dan beberapa masalah medis dan psikososial (Al Sulaiman, 2008). Pemeriksaan skrining infertilitas salah satunya ada analisa sperma bagi laki-laki yang bisa mendeteksi kualitas sperma, gangguan reproduksi yang bisa menyebabkan infertilitas dan memeriksa keteraturan haid pada wanita dan riwayat kesehatan reproduksi pada wanita (Prima, 2011).

Premarital Screening terdiri atas beberapa kelompok tes untuk pasangan yang akan menikah. Tes-tes ini dirancang untuk mengidentifikasi adakah masalah kesehatan saat ini atau yang akan muncul di kemudian hari saat pasangan mengandung/memiliki anak. Sehingga rangkaian kegiatan pencegahan kematian ibu harus dicegah sejak sebelum kehamilan (awal menikah) maka 
pendidikan kesehatan ibu dan anak serta deteksi dini penyakit penyerta sebaiknya dilakukan menjelang pernikahan dan mengetahui kesuburan pasangan (Kompasiana,2016). Dengan adanya premarital skrining untuk mendeteksi infertilitas sekunder diharapkan dapat meningkatkan kualitas pasangan sebelum menikah dan dapat menjadi referensi pasangan nantinya dalam membentuk keluarga yang sehat (Fawcet, 2010). Di negara lain kasus dengan masalah kesuburan bila terdeteksi sejak awal sangat membantu menyelesaikan masalah komunikasi antar pasangan dan kualitas hubungan antar pasangan yang lebih baik (Carrol, 2003).

\section{SIMPULAN}

Bahwa faktor resiko terbesar pada kejadian ibu hamil resiko tinggi adalah dengan riwayat infertilitas sekunder hamil ke-2 > 5 tahun yang berhubungan dengan premarital skrining dengan kesiapan dalam hal anamnesa riwayat kesehatan, pola kehidupan sehari-hari dan keluhan-keluhan gangguan kesehatan reproduksi.

\section{DAFTAR PUSTAKA}

Abu Bakar, Sukawati.2011.Kesehatan Reproduksi Dan Keluarga

Berencana, Jakarta: Rajawali Press

Al Sulaiman, A. Suliman, M. Al Mishari, A. Al Sawadi, T.M. Owaidah.2008. Knowledge and attitude toward the hemoglobinopathies premarital screening program in Saudi Arabia: population-based survey Hemoglobin, 32 (6) (2008), pp. 531538

Carroll, J. S. and Doherty, W. J. (2003)

'Evaluating the Effectiveness of Premarital Prevention Programs: A Meta-Analytic Review of Outcome Research', Family Relations, 52(2), pp. 105-118. doi: 10.1111/j.17413729.2003.00105.x.
Dahlan, Sopiyudin. 2011. Statistik Untuk Kedokteran Dan Kesehatan, Jakarta : Salemba Medika

Dinas Kesehatan Provinsi Jawa Tengah. Profil Kesehatan Provinsi Jawa Tengah

2015.http://dinkesjatengprov.go.id/v 2015/dokumen/profil2015/Profil_201 5 fix.pdf.diakses 25 April 2017

Fawcett, E. B. et al. (2010) 'Do Premarital Education Programs Really Work? A Meta-analytic Study', Family Relations, 59(3), pp. 232-239. doi: 10.1111/j.1741-3729.2010.00598.x

Kompasiana, 2016. Pemeriksaan Kesehatan Pra Nikah, perlukah? http://www.kompasiana.com/pakcah/ pemeriksaan-kesehatan-pranikah. Diakses tanggal 20 juni 2018.

Mulati, Erna dkk. 2015. Buku Ajar Kesehatan Ibu dan Anak, Jakarta : GAVI dan Kemenkes RI

Progestian, Prima. 2011. Pentingnya melakukan pemeriksaan skrining premarital.

http://drprima.com/kandungan/pentin gnya-melakukan-pemeriksaanskrining premarital.html. diakses 28 Juni 2018.

Rochjati, Poedji. 2011. Skrining Antenatal Pada Ibu Hamil, Surabaya: Airlangga University Press

Wiknjosastro, Hanifa. 1999. Ilmu Kandungan, Jakarta : Yayasan Bina Pustaka Sarwono Prawirohardjo

Wikipedia.https://en.wikipedia.org/wiki/Sc reening_(medicine) diakses tanggal 28 juni 2018. 